RAE-IC, Revista de la Asociación Española de Investigación de la Comunicación

vol. 8, núm. 16 (2021), 356-398

ISSN 2341-2690

Recibido el 2 de agosto de 2021

DOI: https://doi.org/10.24137/raeic.8.16.17

Aceptado el 20 de septiembre de 2021

(c) (1) (2)

\title{
Análisis de la representación de la masculinidad en la publicidad impresa contemporánea. Estudio de Caso de la Revista Gentleman's Quarterly España
}

Analysis of Masculinity Representation in Contemporary Print Advertising. Case Study of the Gentleman's Quarterly Spain Magazine

Méndiz Noguero, Alfonso

Universitat Internacional de Catalunya (UIC)

amendiz@uic.es

Caballero Mejía, Natalia

Universitat Internacional de Catalunya (UIC)

natcaballero@uic.es

González Romo, Zahaira Fabiola

Universitat Internacional de Catalunya (UIC)

zfgonzalez@uic.es

Forma de citar este artículo:

Méndiz Noguero, A., Caballero Mejía, N. y González Romo, Z. F. (2021). Análisis de la representación de la masculinidad en la publicidad impresa contemporánea. Estudio de Caso de la Revista Gentleman's Quarterly en España. RAE-IC, Revista de la Asociación Española de Investigación de la Comunicación, 8(16), 356-398.

https://doi.org/10.24137/raeic.8.16.17

RAE-IC, Revista de la Asociación Española de Investigación de la Comunicación vol. 8, núm. 16 (2021), 356-398 


\section{Resumen:}

Tomando como base el alto grado de influencia que tiene la publicidad en la configuración de las identidades de los hombres contemporáneos, así como en la construcción y reconstrucción del concepto de masculinidad, el presente estudio busca ampliar el debate en torno a la representación de los hombres en la publicidad impresa mediante técnicas de análisis de contenido cuantitativas, aplicadas a 137 anuncios aparecidos en doce ediciones del año 2019 de la revista Gentleman's Quarterly España. El estudio ha revelado que en la representación de masculinidad ofrecida en la publicidad prima la comunicación de valores del yo - asociados con características narcisistas y egocéntricas - por encima de los valores colectivos y de solidaridad. Domina en el discurso publicitario la figura del metrosexual entendido como aquel que muestra un creciente interés en prácticas de aseo y de mejoramiento del aspecto físico que han estado históricamente ligadas a las mujeres. Por último, se ha encontrado que las revistas se muestran cada vez más propensas a mostrar expresiones diversas del género, aunque en porcentajes mínimos, recurriendo todavía a herramientas de comunicación típicas como el uso de imágenes idealizadas de hombres prototipo, el empleo de colores históricamente asociados a la masculinidad, y la creciente objetivación del cuerpo masculino a través de elementos gráficos como la mirada y el auto-contacto.

Palabras clave: masculinidad, publicidad, hombre contemporáneo, metrosexualidad, rol de género.

\section{Abstract:}

Based on the high degree of influence that advertising has on the configuration of contemporary men's identities, as well as on the construction and reconstruction of the concept of masculinity, this study seeks to broaden the debate around the representation of men in print advertising using quantitative content analysis techniques, applied to 137 advertisements contained in twelve 2019 editions of Gentleman's Quarterly Spain magazine. The study has revealed that in the 
representation of masculinity offered in advertising, the communication of values of the self - associated with narcissistic and egocentric characteristics - prevails over collective values and solidarity. The figure of the metrosexual, understood as one who shows a growing interest in grooming and physical improvement practices that have historically been linked to women, dominates the advertising discourse. Finally, it has been found that magazines are increasingly prone to showing diverse expressions of the genre, although in minimal percentages, still resorting to typical communication tools such as the use of idealized images of prototype men, the use of historically associated colors. to masculinity, and the increasing objectification of the male body through graphic elements such as gaze and self-contact.

Keywords: masculinity, advertising, contemporary man, metrosexuality, gender role.

\section{INTRODUCCIÓN}

Como producto de la existencia de la estrecha relación entre la comunicación masiva y determinados constructos sociales, y después de la cúspide del movimiento de liberación de las mujeres en los años 60's-80's, numerosos estudios de investigación se comenzaron a realizar para analizar las formas en las que las mujeres son representadas en los medios populares (Schroeder y Zwick, 2004). Estas investigaciones se han centrado en estudiar las implicaciones detrás del constante deseo de alcanzar el "ideal" retratado por los medios, los efectos que esta comunicación tiene sobre la percepción que tienen las mujeres de sí mismas, las diversas definiciones que históricamente ha propagado la publicidad sobre la feminidad y las consecuencias de restringir el comportamiento de las mujeres a una serie de actitudes estereotipadas, y los cambios que ha habido en el papel que juegan las mujeres en la sociedad a través de su representación en la comunicación de masas (Mason, 2003). Sin embargo, a pesar de su inmensa relevancia, pocos estudios, entre los que podemos incluir los de Knutson y Waldner (2017) han sido realizados para investigar este mismo fenómeno pero aplicado a los hombres y solo recientemente se ha comenzado a prestar una atención similar a la relación que existe entre el concepto de masculinidad y la comunicación masiva. 
Diferentes estudios se han enfocado en investigar las maneras y los cambios que ha habido en las definiciones de masculinidad propagadas por los medios populares, especialmente en el mundo occidental. Autores como Gardiner (2002) han señalado que la masculinidad hegemónica provoca la marginalización de algunos hombres al obligarlos a cumplir roles confinados, desaprobar la exhibición de emociones, restringir sus relaciones con otros hombres, limitar su conciencia social, y distorsionar su autopercepción, condenándolos a vivir con el temor constante de no estar a la altura del ideal masculino.

Sin embargo, muchos otros han llegado a la conclusión de que nos encontramos en un momento en el que nuevas y variadas definiciones de masculinidad, tales como la metrosexualidad, el género andrógino (Messner, 2000 o la figura reciente del padre cuidador (Leader, 2019), están comenzando a ser retratadas en la publicidad, y consecuentemente, están encontrado una aceptación cada vez mayor por parte de la sociedad en general.

\section{MARCO TEÓRICO}

\subsection{LA PUBLICIDAD Y LA MASCULINIDAD}

Algunas investigaciones argumentan que la representación de normas de género y de estereotipos en la publicidad ha ido disminuyendo y, en cambio, están surgiendo representaciones más diversas y flexibles (Berkery et al., 2013; Ford et al., 1998; Mager y Helgeson 2011; Wolin, 2003). Por ejemplo, Wolin (2003), después de realizar una síntesis de tres décadas de publicidad relacionada a la representación de género, ha sugerido que el uso de estereotipos de género ha disminuido, dando entrada a representaciones más realistas. De manera similar, después de estudiar retratos de hombres y mujeres en anuncios de revistas durante un periodo de 50 años, Mager y Helgeson (2011) encontraron una tendencia constante hacia la igualdad de género en el área de representación de roles y un disminución general en el uso de estereotipos de género en la publicidad durante el periodo comprendido entre los años 1970 a 2002. Por lo tanto, algunas investigaciones sugieren que los cambios en la representaciones del género en los medios de comunicación son consistentes con los cambios en las 
tendencias sociales y culturales prevalecientes (Kacen, 2000; Leiss et al., 2005; Mager y Helgeson, 2011; Screti, 2019).

Si bien se está produciendo un cambio social, se encontró que la publicidad continúa propagando roles y normas estereotipadas (Gentry y Harrison, 2010). De manera similar, Vranica (2003) sostiene que a pesar de que la publicidad y el movimiento hacia la igualdad de género a menudo se entrelazan, la hipersexualización de la mujer y el uso de estereotipos sexuales aún persisten en la publicidad moderna.

Ahora bien, para poder determinar el estatus actual de la publicidad con respecto a los roles de género resulta necesario primero llevar a cabo un análisis de la evolución de la relación que han tenido la publicidad con el género, específicamente el género masculino, a través de los años.

Las investigaciones de estilo de vida y psicográficas realizadas hasta ahora han indicado la existencia de un nuevo conjunto de hombres "innovadores" cuyas actitudes "contemporáneas" y de "autoconsciencia" hacia la masculinidad y el consumo los ha hecho cada vez más receptivos a los recursos editoriales y publicitarios utilizados en revistas y otros soportes publicitarios (Crewe, 2002). La imagen masculina vendida actualmente es aquella de un hombre preocupado por sí mismo y por sus metas personales, la cual ha sustituido a la imagen del hombre de familia y proveedor principal del hogar que había sido vendida anteriormente (Crewe, 2002). A esta nueva representación se le ha otorgado el potencial de socavar las concepciones tradicionales de masculinidad, dándole especial atención a la creciente exposición del cuerpo masculino en las nuevas imágenes (Crewe, 2002).

Las asociaciones de poder, rendimiento y precisión que se le otorgan a los productos reflejan el nivel de poder físico y financiero del consumidor masculino que decide comprarlo (Rohlinger, 2002). Sin embargo, en los roles de género representados a través de la publicidad actual, los hombres son cada vez más capaces de operar dentro de ambos roles: en el rol femenino de complacerse y ser complacido, y en el rol masculino de exigencia, competencia y poder (Rohlinger, 2002). En otras palabras, debido a que las delimitaciones de los roles de cada género se han ido relajando, muchos anunciantes han 
recurrido a representar un comportamiento cruzado o mixto de comportamientos y roles de género en sus anuncios como ya lo expresa Leader (2029). La legitimidad de esta práctica está basada en que la demografía de los consumidores más deseables para los anunciantes (jóvenes, solteros, profesionales, nivel alto de ingresos, urbanos y bien educados) también son los que tienen menos probabilidades de comprar productos que representan roles de género tradicionales. Este conjunto de cambios culturales han incrementado los niveles de receptividad de los hombres hacia los mensajes publicitarios además de dar lugar a lo que es conocido como "el hombre nuevo" (Crewe, 2002).

Este hombre nuevo, el cual se usa para vender desde ropa hasta artículos de cuidado personal, parece que está rompiendo con convenciones, ya que invita a los hombres a disfrutar de sí mismos y de otros como objetos sexuales, y a cuidar de su aspecto tal como lo harían las mujeres (Crewe, 2002). La proliferación y aceptación por parte del público de este "hombre nuevo" ha provocado que los anunciantes se den cuenta de que las líneas que diferencian a los hombres de las mujeres están disminuyendo.

Muchos anunciantes se han dado cuenta de que los hombres también son únicos y desean un cambio, un cambio que quizás culmine en un papel igualitario de hombres y mujeres como consumidores y compradores, y que también acepte y promueva varios tipos de masculinidad y no solamente una masculinidad rígida y hegemónica (Crewe, 2002). Estos cambios en la cultura comercial, han provocado el surgimiento de una serie de identidades posibles para los hombres que se han consolidado en lo que algunas investigaciones han catalogado como "distintos tipos de masculinidad". Entre ellos, y quizás el más conocido de todos, es la metrosexualidad, concepto que retomaremos más adelante.

\subsection{INVESTIGACIONES ANTERIORES REALIZADAS SOBRE LA PUBLICIDAD EN REVISTAS}

\section{MASCULINAS}

A lo largo de los años, aunque en una cantidad mucho menor a los realizados en cuanto a mujeres, en múltiples investigaciones se han realizado estudios sobre los efectos y las consecuencias de la publicidad contenida en revistas dirigidas a hombres. Los resultados e hipótesis obtenidos en ellos han servido como base para otros y más variados estudios, 
y han ayudado a tener una mejor comprensión del desarrollo que ha tenido el concepto de la masculinidad no solamente en la publicidad moderna sino también, y tal vez más importante, en la sociedad a un nivel macro. Todos estos proyectos han partido de la afirmación de que existe una interacción continua entre el marketing y la sociedad (Hall et al., 1997) y también de la premisa de que las imágenes publicitarias son consideradas artefactos culturales y portadoras de significado, que reflejan amplios códigos sociales, culturales e ideológicos. La interpretación de imágenes masculinas en anuncios publicitarios contemporáneos son lugares particularmente útiles para analizar las respuestas que se le han dado a la pregunta "¿Qué significa ser un hombre?" a lo largo de los años y de las sociedades (Stern, 2003). Además, a través de este tipo de análisis también se pueden buscar respuestas a otras preguntas; ¿Cómo la transformación dentro de anuncios publicitados expresa contradicciones y conflictos sobre la identidad masculina? ¿Cómo afecta la propagación del ideal vendido por las imágenes publicitarias al autoestima y desenvolvimiento de los hombres a lo largo de las diversas etapas de su vida? ¿Cómo influye el miedo a la homosexualidad en la representación publicitaria?, entre muchas otras.

En un intento por contestar estas y muchas otras preguntas, investigaciones anteriores han indagado cómo los hombres y las masculinidades han sido retratadas en las revistas de estilo de vida populares actuales (Alexander 2003; Benwell 2004; Canape 1985; Taylor 2005; Vigorito y Curry 1998).

Boni (2002), al observar la edición italiana de Men's Health, argumentó que el éxito de la revista en el mercado italiano es un reflejo de las relaciones e identidades de género cambiantes. Además, descubrió que los medios populares globales representan un solo tipo de masculinidad; la masculinidad hegemónica. Nixon (1996) exploró los cambios publicitarios en las revistas de hombres (la codificación visual de la masculinidad) para explicar la formación de imágenes metrosexuales dentro de la publicidad. Encontró que la masculinidad, tal como la presentan los modelos en anuncios publicitarios era asertiva, suave y sexualizada. En general, señaló que el estilo de la moda masculina en las revistas estaba orientado a los nuevos consumidores masculinos más jóvenes y 
aceptaba los cambios en su estilo de vida; por tanto, veía a las revistas como un reflejo de los cambios en el concepto de masculinidad.

Jackson et al. (2001) accedieron a la construcción discursiva del género a través de discusiones verbales con los encuestados, encontrando un alto nivel de ambivalencia en la forma en que los lectores discuten las revistas masculinas y el concepto que se vende de masculinidad. Llegaron a la conclusión de que llevar a cabo un análisis simple de la masculinidad, incluida la masculinidad hegemónica, no era posible. En cambio, argumentaron que las revistas para hombres ofrecen a sus lectores un "mapa conceptual para navegar de manera segura a través de sus inquietudes de género contemporáneas, ya sea en relación con su salud, sus carreras, sus relaciones sexuales o su lugar en la "cultura del consumidor en general" (p.p. 14). En general, se encontró que las revistas simbolizan una mercantilización de los problemas de género que experimentan los hombres y abren un espacio en el que se emplean dispositivos tales como el humor, el desafío y la ironía, para alejar a los hombres de cualquier compromiso significativo con el cambio colectivo o con el personal (Jackson et al. 2001).

Con respecto a la sexualidad, los estudios indican que los hombres se representan con mayor frecuencia bajo una luz "desconocida" o "ambigua" cuando se trata de su sexualidad. En otras palabras, los consumidores a menudo son incapaces de identificar positivamente la sexualidad de los modelos masculinos en los anuncios publicitarios. Sin embargo, cuando es posible determinar la sexualidad, los modelos generalmente se identifican como heterosexuales (Cutler, 2007). En un estudio de anuncios en revistas, Rohlinger (2002) encontró que los modelos masculinos nunca se mostraban abiertamente bajo una luz homosexual. Sus hallazgos sugieren que el cuerpo masculino es vendido como "un lienzo en blanco en el que el espectador puede proyectar el significado que quiera" (2001, p. 71). Esto permite al espectador imaginar el cuerpo masculino en cualquier situación sexual; heterosexual, homosexual, bisexual, y garantiza que los anunciantes no asusten a sus espectadores heterosexuales (Cutler, 2007).

En uno de los estudios más recientes, Lay (2018), se propuso analizar cómo la publicidad representaba el género en el 2017 y cómo la publicidad ayuda a la sociedad a 
comprender las normas de género vigentes. En él, Lay concluyó que, con las tendencias crecientes de la metrosexualidad y del afeminamiento en los hombres, los estereotipos asociados con la masculinidad tradicional propuestos por la publicidad se han reducido en mayor grado que los estereotipos asociados con la feminidad.

\subsection{EL NACIMIENTO Y EL AUGE DEL METROSEXUAL}

En noviembre de 1994, el escritor y comentarista cultural británico Mark Simpson escribió un artículo titulado "Here Come the Mirror Men", en el periódico británico The Independent en el cual hacía referencia a un creciente segmento de jóvenes conscientes de su estilo. Simpson acuñó el término "metrosexual" para describir a estos "jóvenes narcisistas que lucen ropa y accesorios de moda" (Simpson, 1994). El término encontró poca resonancia en años siguientes y no fue hasta julio del 2002, cuando Simpson reintrodujo el término en otro artículo publicado en el portal salon.com titulado "Meet the Metrosexual - he's well dressed, narcissistic and obsessed with butts. But don't call him gay", que el termino comenzó a adquirir relevancia a nivel internacional. En este nuevo artículo, Simpson "expuso" a esta nueva generación de jóvenes conscientes del estilo, como David Beckham y Brad Pitt, como metrosexuales. Proporcionó la siguiente descripción del metrosexual, la cual ha sido citada con frecuencia desde su publicación:

“El típico metrosexual es un hombre joven con dinero para gastar, que vive en o cerca de una metrópolis - porque es allí donde se encuentran las mejores tiendas, discotecas, gimnasios y peluquerías. Puede ser oficialmente gay, heterosexual o bisexual, pero esto es absolutamente irrelevante porque, claramente, se ha tomado a él mismo como el objeto de amor y de placer como su preferencia sexual. Se pueden encontrar en profesiones tales como el modelaje, los medios de comunicación, la música pop, e incluso los deportes pero, ha decir verdad, tal como los productos de tocador para hombres y el herpes, hoy en día están prácticamente en todas partes" (Simpson, 2002).

Simpson ofrece a David Beckham, el futbolista británico casado con la ex Spice Girl Victoria, como el ejemplo por excelencia del metrosexual. Beckham es tan notorio por su extravagante atención a su imagen estética como lo es por sus habilidades deportivas, convirtiéndolo en una opción ideal para profesionales del marketing que buscan 
promociones para productos y complementos de moda masculina (Pietsch, 2004). En su artículo, Simpson clasifica a Beckham como "un narcisista de nivel internacional", sugiriendo que representa una nueva versión de la virilidad; una que adora verse bien y sentirse y ser mirado por otro.

Una de las características que diferencia a Beckham, y por lo tanto a los metrosexuales, de los arquetipos anteriores de masculinidad consciente del estilo, es que busca activamente una mirada indiferenciada (Pietsch, 2004). En una entrevista con Beckham para la revista gay británica Attitude en 2002, el futbolista confirmó ser heterosexual, pero también expresa su satisfacción por ser considerado un ícono gay. Simpson sostiene que la parte sorprendente de la aparición de Beckham en Attitude, además de ser una figura deportiva importante en una revista gay, fue la poca controversia que causó. Simpson sostiene que este suceso es lo que representa una cambio significativo en las normas contemporáneas de la masculinidad (Simpson, 2002).

La segunda mención de Simpson de los metrosexuales en el artículo publicado en el 2002 llegó en un momento en el que los medios de comunicación y los publicistas estaban ansiosos por encontrar un término que describiera esta nueva versión de masculinidad consumista y consciente de su imagen que se estaba ganando cada vez más presencia y coherencia (Pietsch, 2004). Lo que comenzó como una caracterización un poco satírica de un nuevo segmento de consumidores, se terminó por transformar en una potente herramienta de marketing y en una sensación mediática. En los años que han pasado después de esta publicación, el metrosexual se ha ido separando paulatinamente de sus orígenes un tanto despectivos, y se ha ido reforzando como un arquetipo de masculinidad simpático, quizás incluso deseable, para el hombre contemporáneo (Pietsch, 2004).

Ahora bien, aunque en la definición original de Simpson del metrosexual citada anteriormente se indica que la orientación sexual del metrosexual es irrelevante, ya sea homosexual, heterosexual o bisexual, en la mayor parte de la literatura y de los estudios de medios, los metrosexuales se han configurado constantemente como heterosexuales. Simpson sugiere que fueron los hombres homosexuales quienes 
propiciaron un prototipo temprano de la metrosexualidad (Simpson, 2002). De hecho, mientras que los hombres homosexuales han estado estereotípicamente con un fuerte sentido estético, fue la novedad de un hombre heterosexual muy preocupado por el estilo lo que captó la atención de los medios y el público (Pietsch, 2004).

Desde mediados del siglo XX, los hombres homosexuales han actuado como marcadores de tendencias de la moda masculina en general (Emig, 2000). Ahora, los estilos y las modas originados por la minoría gay han sido adoptados por la mayoría heterosexual. Simpson sostiene que los metrosexuales se han convertido en los nuevos líderes de la moda; "los gays urbanos conscientes de la moda pueden haber proporcionado el prototipo para la metrosexualidad, pero son la versión beta que ha sido descartada". El metrosexual ha desplazado a los homosexuales como creadores de tendencias para la moda masculina, y los mercadólogos lo han notado y lo han estado usando a su favor (Pietsch, 2004).

Los mercadólogos consideran a los metrosexuales como líderes de estilo, que brindan información importante acerca del desarrollo de la masculinidad normativa (Pietsch, 2004). Lo que diferencia a los metrosexuales de hoy en día de sus antepasados es su actitud despreocupada ante la inevitable sospecha de que un hombre que se viste bien, tiene buenos modales y tiene opiniones sobre la moda femenina, es gay (St John, 2003). En la mayoría de los casos, los periodistas han retratado la adopción de un sentido estético más intenso por parte de los hombres bajo una luz favorable; Hood (2003) enmarca a la metrosexualidad como un movimiento emancipador que permite a los hombres acceder a dominios femeninos que anteriormente se habían considerado prohibidos o tabú; Larsen (2004) afirma que el metrosexual ha perdido todas las connotaciones negativas que pudo haber tenido originalmente y atribuye el surgimiento de los metrosexuales a los cambios en las normas de masculinidad; Mirchandani (2004) clarifica que las tendencias metrosexuales no afectan la virilidad de los que las practican, sosteniendo que los metrosexuales pueden ser tan duros y atléticos como cualquier otro hombre pero simplemente hacen todo con más estilo y elegancia. 
A finales del 2003, el concepto del metrosexual tomó más forma con el lanzamiento de Michael Flocker de un manual titulado "The Metrosexual Guide to Style: A Handbook for the Modern Man". Este manual proporciona los medios necesarios para convertirse en un jugador dentro del mundo y la era de la metrosexualidad; la guía de 170 páginas ofrece consejos sobre temas que incluyen etiqueta, cultura, moda, aseo y decoración, así como listas de las cosas que se deben hacer y no hacer, o cosas que se tienen q tener o no tener.

Básicamente, Flocker sostiene que los hombres contemporáneos han evolucionado a una forma más deseable de masculinidad. "La nueva raza de hombre es única en su estilo, sofisticación y autoconciencia. Es tan fuerte como su predecesor pero mucho más diverso en sus intereses, sus gustos y, lo que es más importante, su autopercepción. Seguro de su masculinidad, no tiene que pasar su vida defendiéndola" (Flocker, 2003).

El manual de Flocker difiere de otras guías de estilo masculino anteriores gracias a algunas distinciones notables; en la primera página de la introducción, Flocker declara "la gran división entre hombres heterosexuales y hombres homosexuales ha disminuido considerablemente en los últimos años". Flocker considera que los metrosexuales representan una distorsión de las categorías de hombres heterosexuales y homosexuales, sugiriendo que es aceptable y deseable que un hombre heterosexual se confunda con un hombre gay, "hay un cierto poder y misterio en la ambigüedad" (xii). Flocker alienta a los aspirantes a metrosexuales a disfrutar $\mathrm{d}$ el mirada indiferenciada del otro, en la sección de sexo y romance comienza con algunos consejos sobre la diversidad: "el hombre metrosexual disfruta de una atención positiva y se siente libre de coquetear con mujeres y hombres de una manera alegre y divertida. El coqueteo es inofensivo y la adulación es solo eso - adulación. Entonces relájate, diviértete y sé quien quieres ser" (p. 132). Flocker no solamente reconoce la mirada homoerótica, sino que busca que los metrosexuales la busquen activamente a través del coqueteo. La versión de la masculinidad presentada por Flocker representa un cambio radical con respecto a la noción de Mulvey de una masculinidad que evade la mirada. Es la relación que tiene el metrosexual con lo homoerótico y lo homosexual lo que diferencia a la masculinidad planteada por Flocker de otros tipos anteriores de masculinidad (Pietsch, 2004). 


\subsection{LA METROSEXUALIDAD Y EL SURGIMIENTO DEL HOMBRE QUE SE PREOCUPA POR} SU ESTILO

Los últimos veinte años han visto un cambio considerable en la relación que tienen los hombres occidentales con la moda, su estilo personal y sus cuerpos. Actualmente, el cuerpo masculino aparece en casi todas partes y se usa para vender desde ropa interior hasta bebidas refrescantes e incluso automóviles (Pietsch, 2004).

El advenimiento de esta generación ha provocado que tanto mercadólogos como medios de comunicación se interesen por estas nuevas inclinaciones estéticas y nuevos comportamientos mostrados por los hombres. (Pietsch, 2004). A partir de este interés ha surgido un debate en donde algunas investigaciones sugieren que concepto de metrosexualidad es solamente una etiqueta promovida por compañías de investigación de mercado, agencias de publicidad, revistas de consumidores y comercializadores para etiquetar y legitimar los comportamientos de un segmento de consumidores con el fin de rentabilizarlo (Benwell, 2004). Mientras que otras investigaciones (Nixon, 1996) consideran el concepto de la metrosexualidad un fenómeno social multidimensional y genuino, producto de la convergencia entre elementos como la sociedad moderna de consumo, la crisis del sistema binario de género y los avances de movimientos sociales, principalmente el feminismo y el movimiento LGBTIA.

Para conceptualizar la metrosexualidad es necesario comenzar con la definición de un metrosexual como un "creador masculino de tendencias del siglo XXI; hombre heterosexual, urbano, con un sentido estético elevado, que invierte tiempo y dinero en su apariencia y en las compras, y que está dispuesto a abrazar su lado femenino" (Flocker, 2003). El primer aspecto que caracteriza a esta generación es el estar al día con las tendencias de moda. Dicho involucramiento continúa siendo de gran interés para investigadores ya que, aunque a menudo las mujeres jóvenes participan más que los hombres en cuestiones de moda, se considera que los metrosexuales tienen sensibilidad para captar, marcar y/o establecer tendencias, siendo conocidos por su capacidad para marcar y establecer nuevas tendencias (Segal y Podoshen, 2014; Flocker, 2003). 
Algunos de sus rasgos característicos son: heterosexualidad, viven o trabajan en la ciudad, tienen un nivel alto de ingresos económicos, son vanidosos, solteros, y jóvenes. Se les atribuyen una serie de comportamientos como; interés alto en su apariencia, rutinas habituales de aseo personal, asistencia regular a peluquerías y spas, gusto por la moda, asistencia regular al gimnasio, gusto por la buena comida. Tienen actitudes características como estar dispuestos a consentirse a sí mismos y tendencia al narcisismo. Cuentan con ciertos valores característicos como el saber qué es lo que quieren y una inclinación por hacer lo que les plazca, así como estar orientados a la familia. Por último, se considera que los metrosexuales se esfuerzan por ser un objeto de deseo para los demás, acogiendo la atención de las mujeres y de los hombres (Simpson, 2002; Flocker, 2003; Gotting, 2003; Salzman et al., 2005; Flocker 2003; Lempert, 2004).

A partir de estos rasgos característicos y definiciones, el estilo de vida metrosexual se puede conceptualizar en base a tres elementos interrelacionados: estar a la moda, gran preocupación por la apariencia física, y la aceptación y el uso de múltiples prácticas de aseo personal (Mitchell, 2017). Además, de estas definiciones también se pueden comenzar a discernir algunos de los antecedentes psicológicos posibles y relevantes de la metrosexualidad, como la identidad de género, la masculinidad, la feminidad, la orientación sexual, y la vanidad (Mitchell, 2017).

\section{METOdOLOGÍA}

El presente estudio pretende analizar la representación de la masculinidad en la publicidad impresa contemporánea en el mundo occidental; analizando la calidad y el tipo de valores con los que se le asocia, buscando la prevalencia de estereotipos, de arquetipos, y de patrones dominantes que puedan sugerir la existencia de un "hombre nuevo" consciente de su estilo y preocupado por su aspecto físico, también conocido como metrosexual.

El estudio parte del interés de conocer la representación masculina en la publicidad impresa occidental actual analizando los arquetipos actuales del hombre, de entre los cuales nos interesa conocer: 
- Si el estereotipo del hombre trabajador, líder de familia, se ha quedado atrás y ha sido sustituido por el de un hombre interesado solamente en sí mismo, en el placer, en el disfrute y en el ocio, dejando poca cabida para el desarrollo de relaciones interpersonales de calidad.

- Si el arquetipo actual de masculinidad es distinto a arquetipos que han dominado el discurso publicitario en el pasado debido a su creciente interés en temas que han estado históricamente asociados a las mujeres y la feminidad - la moda, la imagen y las técnicas de belleza - permitiendo que la figura masculina haya pasado de ser el tradicional "observador", a la posición del "observado" dentro de la configuración del discurso publicitario.

- Si la representación del hombre moderno se asemeja cada vez más al tipo de representaciones que se han utilizado para dirigirse a mujeres durante años y que varias generaciones de movimientos sociales han tratado de erradicar debido a los efectos adversos que tienen en la psique y autopercepción de los consumidores; una representación llena de estereotipos, ideales inasequibles, y representaciones utópicas.

Por lo que este estudio se centra en una serie de objetivos, enumerados a continuación:

a. Comprobar si el arquetipo de la metrosexualidad es el normativo dentro de la sociedad actual y hasta qué grado la publicidad impresa lo acepta e incluso lo perpetúa a través de sus imágenes y representaciones.

b. Identificar los principales valores que la publicidad impresa contemporánea le asocia a la masculinidad a través de la representación gráfica de los sujetos masculinos y técnicas descriptivas que emplea en sus anuncios.

c. Analizar la manera en la que el sujeto masculino es representado actualmente a nivel tanto técnico como descriptivo en la publicidad impresa, intentando encontrar patrones y temáticas recurrentes dentro del discurso y mensaje publicitario. 
d. Esbozar posibles relaciones relevantes entre variables que conforman el mensaje publicitario y comercial impreso, intentando encontrar aquellas que tengan mayor reincidencia.

El corpus teórico de este estudio está compuesto por todos los anuncios de publicidad impresa en los que se puede ver la presencia de un modelo masculino, contenidos en 12 ediciones de la revista Gentleman's Quarterly España, desde enero hasta diciembre de 2019. Se decidió analizar únicamente anuncios que aparecen en la revista Gentleman's Quarterly debido a su relevancia social, popularidad y alta circulación. En su media kit del 2018 se definen a sí mismos como "Más que una marca prescriptora; [GQ] es el amigo que orienta al hombre en todo lo relativo a tendencias y le ayuda a crecer como individuo a través de su aspecto, ideas y decisiones...GQ tiene el compromiso de ser el descodificador del hombre del S.XXI... GQ no solo es moda, es todos los temas que modulan el debate actual y redefine el papel del hombre en la sociedad" (Conde Nast Media Kit 2017) GQ cuenta con ediciones en 19 mercados alcanzando más de 7 millones de lectores en el mundo occidental (GQ media kit, 2017), presentes en España desde hace 24 años con más de 57 mil lectores, más de 800 mil followers y arriba de los dos millones de usuarios (Media kit GQ España 2018). Es la revista líder en ocupación publicitaria con un $20 \%$, por encima de publicaciones como Esquire, Forbes, Men's Health, entre otras.

La selección y el recuento de los anuncios analizados estuvo delimitado por los siguientes factores:

El presente estudio se realizó a través de un análisis cuantitativo de contenido que se define como un examen sistemático y cuidadoso de un cuerpo particular de material en un esfuerzo por identificar patrones, temas, sesgos y significados (Berg y Lune, 2012). Más específicamente, un análisis de contenido cuantitativo es el examen de símbolos de comunicación a los que se les ha asignado un valor numérico de acuerdo con reglas de medición válidas para generar inferencias sobre patrones y temas de relevancia en el mundo social (Riff et al., 2014). 
El nivel de medición utilizado en el estudio es el nominal, ya que cada categoría que ha sido sometida a análisis, contenida dentro de las diferentes variables, Esta modalidad nominal aplicada a investigaciones en medios de comunicación resulta útil ya que convierte a todas las categorías en mutuamente excluyentes y exhaustivas (Medina, 2011). Se pueden observar las variables que sirven a esta investigación en el apartado de anexos.

Las variables y categorías seleccionadas para el análisis técnico y descriptivo, las cuales pretendían indagar sobre la composición del anuncio así como en la representación de los sujetos masculinos, fueron adaptadas de estudios e investigaciones realizadas anteriormente por autores como Cutler (2007), Mason (2003), Medina (2011), Harper (2013), Pietsch (2004), Méndiz (2005) y Lay (2018).

Las variables agrupadas bajo el denominador "Nuevas Categorías" fueron obtenidas del trabajo de investigación de Taylor Lay (2018) en donde pretendía explorar si los medios de comunicación contemporáneos están ampliando sus comprensiones y representaciones de género en sus mensajes o si siguen apegándose a representaciones estereotípicas y tradicionales. En la siguiente sección las dos variables establecidas bajo este denominador serán exploradas con mayor detenimiento.

En los anexos se incluye una tabla que recoge y sintetiza las categorías y variables que han sido utilizadas para categorizar el análisis de los 135 anuncios recopilados en 12 ediciones de la Revista GQ España en el año 2019.

\section{RESULTADOS E INTERPRETACIÓN}

Dentro de la muestra analizada el 59\% de los productos publicitados cayeron dentro de la categoría "Textil, vestimenta y calzado", seguido por "Joyería y Accesorios" con un 18\%, "Cosmética y belleza" con un 10\%, y "Bebidas Alcohólicas" con un 4\%. No hubo ningún producto que cayera dentro de las categorías de "Higiene personal", "Viajes, turismo y transporte de personas", "Productos tecnológicos relacionados con el trabajo", "Tecnología”, “Alimentación y bebida”, "Videojuegos”, “Cigarros”, “Equipo de ejercicio" y "Entretenimiento". 
De los resultados obtenidos en esta variable, cabe destacar la presencia dominante de anuncios publicitado productos relacionados con la moda, ya sean vestidos, accesorios o productos de belleza. Sin embargo, cabe también hacer hincapié en el hecho de que, debido a que dentro de la muestra se han descartado anuncios que no contaran con un sujeto masculino, se han dejado fuera varios anuncios que solo mostraban el producto y que en su mayoría promocionaban: automóviles y productos relacionados (neumáticos, combustibles), productos de higiene personal (cremas para afeitar, desodorantes, etc), bebidas alcohólicas (mayoritariamente licores), y relojes.

Dentro de la variable "Marca", Gucci fue la marca con más anuncios publicados con un total de 7 anuncios para el año 2018, seguido por Hugo Boss y Dolce \& Gabanna. Algo interesante a destacar dentro de los resultados de esta variable, es el alto grado de exposición de publicidad de marcas que son consideradas de lujo en el mundo de la moda. Nombres como Emporio Armani, Dolce \& Gabbana, Gucci, Hermés, Michael Kors, Prada y Versace han sido las marcas con mayor número de publicidad impresa publicada en la muestra analizada. Estas marcas forman parte de un nicho de diseñadores de moda de lujo y renombre que se dirigen a un público objetivo concreto; aquel compuesto por personas que gozan de un cierto nivel adquisitivo y que conforman los estratos altos de la sociedad en términos socioeconómicos. La lectura de estos resultados permite hacer inferencias acerca del público objetivo de la revista en cuestión, el cual muy probablemente esté compuesto por adultos jóvenes con un nivel alto de estudios académicos, que se encuentren desempeñando roles directivos o de niveles altos de responsabilidad, dentro de grandes metrópolis del mundo occidental.

En cuanto al color predominante en los anuncios, la categoría "Ninguno" ha sido la más recurrente con un "34\%", seguido por la categoría "Negro" con un 26\%, y "Azul” con un 15\%. Ningún anuncio ha sido catalogado bajo "Naranja”. De acuerdo a estos resultados, a nivel composición, la publicidad sigue recurriendo a elementos que históricamente han estado asociados con los hombres y la masculinidad. La alta prevalencia en el uso de los colores negro, rojo, y azul, evidencian que el mensaje publicitario dirigido a hombres sigue implementando el uso de colores cuyas asociaciones principales son la 
masculinidad, la juventud, la fuerza, la frialdad, la sabiduría, el poder, la elegancia, la templanza, etc.

Algo muy interesante que se ha observado durante el estudio con respecto a esta variable, ha sido que en los únicos dos anuncios en los que el color rosa se ha determinado como el dominante, ambos contaban con la presencia de una mujer y ambos sugerían la existencia de algún tipo de vínculo romántico y amoroso, completamente alejado de lo sexual. Es decir, las únicas dos ocasiones en las que el color rosa dominó la composición de los anuncios - un color culturalmente asociado con la feminidad y las mujeres, caracterizado por evocar sentimientos de ternura, suavidad y delicadeza - fueron también las dos únicas ocasiones en las que el anuncio mostraba explícitamente la presencia de una relación romántica entre un sujeto masculino y uno femenino.

Estas dos lecturas de los resultados obtenidos bajo la variable "color predominante" evidencian que, en términos de composición, la publicidad sigue recurriendo a estereotipos culturales que están presentes en la sociedad y que lo han estado durante décadas; el azul es de hombres y para todo lo que típicamente ha estado asociado a ellos - el poder, la frialdad, la fuerza - y el rosa es para mujeres y su suavidad, su ternura y su dependencia en relaciones románticas. Para el análisis del valor asociado al producto, la categoría "Elegancia, estilo, estético, artístico" ha tenido la mayor reincidencia con un 23\%, seguido por "Belleza, atracción y seducción" con un 16\%, "Novedad" con un $8 \%$ y "Placer" y "'Calidad" ambos con un "7\%". Ninguno de los anuncios analizados han caído dentro de las categorías "Comprensión, ternura", "Poder", "Respeto a los mayores, madurez, tradición", "Sabiduría, afán de saber", "Salud", "Seguridad y protección", "Solidaridad, ayuda" y "Trabajo, esfuerzo".

Tal como se ha comentado en el apartado correspondiente al establecimiento de la metodología y la muestra, la inclusión de la categoría "Elegancia, estilo, estético, artístico" se evaluó como necesaria una vez comenzado el estudio, al notar que ninguna de las otras variables establecidas hacían referencia a aquellos anuncios en donde el valor asociado al producto era algo meramente estético. Una vez terminado el estudio, 
esta variable incluida a posteriori, ha sido la que ha tenido mayor reincidencia dentro de la muestra. La lectura de este fenómeno resulta sumamente interesante, ya que, por un margen bastante amplio, todos los valores asociados con el hedonismo, narcisismo y egocentrismo han sido los dominantes, por encima de valores asociados con lo colectivo y las relaciones interpersonales tales como la familia, la colectividad, la solidaridad y la amistad.

La fase de análisis descriptivo del estudio ha consistido en un detenido análisis de la manera en la que se representa al personaje masculino encontrado en los anuncios, esta fase del estudio ha comenzado con la observación de la edad de cada uno de los sujetos. La categoría con mayor porcentaje ha sido el intervalo que contiene los años considerados como la "segunda juventud" del ser humano con un $43 \%$, seguido por la "primera juventud" con un $23 \%$ y la primera edad adulta" con un "16\%". La edad de ninguno de los sujetos ha entrado dentro de las categorías de "primera infancia", "Segunda infancia”, "adolescencia” y “vejez".

Al igual que la variable "marca", este apartado permite hacer inferencias sobre el target al cual se dirige la revista analizada, el cual probablemente está compuesto por hombres cuya edad oscila entre los 24 y los 55 años.

En cuanto al color de cabello de los sujetos masculinos, la categoría "Moreno" ha obtenido el mayor porcentaje con un 54\%, seguido por "Rubio" con un $31 \%$ y “Otro" con un $14 \%$.

En la variable "Rasgos Étnicos" la mayoría ha caído dentro de la categoría "Occidental" con un 73\%, seguido por "Afro-americano/africano" e "Imposible Determinar", ambos con un "9\%", este conjunto de categorías permiten indagar un poco más acerca del público objetivo al cual se dirige la revista $G Q$ y la publicidad contenida en ella, intuyendo que, muy probablemente, esté compuesto por hombres que habitan en países del mundo occidental.

En el análisis de la constitución física de los sujetos masculinos encontrados en los anuncios, se ha observado una mayor representación de hombres "Delgados o débiles" 
con un 53\%, seguido por "Imposible determinar" con un $23 \%$ y por hombres considerados "Fuertes o tonificados" con un $20 \%$. Ningún anuncio se ha encontrado dentro de la categoría "Otro" dentro de esta variable.

Las cuatro variables analizadas anteriormente; edad, color de cabello, rasgos étnicos y constitución física, además de ser indicadores que permiten intuir las características del público objetivo al cual se dirige la revista y la publicidad contenida en ella, son también resultados que permiten hacer lecturas más profundas en lo que atañe a la presencia de ideales y representaciones masculinas prototipadas dentro de la comunicación publicitaria dirigida a hombres en el mundo actual.

Mezclando las categorías que han dominado las cuatro variables anteriores, podemos inferir que el "hombre ideal" occidental perpetuado por la publicidad contemporánea es uno que se caracteriza por ser joven, tener cabello claro, presentar rasgos propios de grupos étnicos de países occidentales y más que estar musculoso, su composición física es un punto medio entre la delgadez y la musculatura, es decir, es delgado pero tonificado. En cuanto a la indumentaria usada por los modelos, el estilo "Casual" ha sido el más recurrente con un 39\%, seguido por "Business Casual" con un $23 \%$ y "Elegante" con un 14\%. Ningún anuncio analizado ha caído dentro de la categoría de "Ropa Interior".

En esta variable ha sido relevante la nula presencia de hombres mostrando una vestimenta propia de un hombre trabajador; aquel look serio, típico de oficina, compuesto por un traje, una corbata, y zapatos de vestir. El estilo casual, despreocupado, e incluso en algunas ocasiones desaliñado, ha sido el que ha dominado la indumentaria expuesta en los anuncios. Esto abre una línea de discusión en cuanto al alejamiento por parte de la publicidad, e incluso de la sociedad, de los valores relacionados con el ámbito laboral y profesional, y el progresivo acercamiento y favorecimiento de valores y actitudes que tienen que ver más con la recreación, la despreocupación, el placer, y el disfrute.

A lo largo de la observación llevada a cabo para la concreción de los datos aquí presentados, ha resultado relevante que, en las trece ocasiones en las que se ha visto la presencia de un anillo de boda, ha sido por parte de actores y famosos que se sabe que 
están en una relación de matrimonio, por ejemplo: David Beckham, Justin Timberlake, Brad Pitt. Es decir, en ninguna ocasión se ha mostrado un modelo que no fuera algún famoso, que tiene un matrimonio público y conocido por la audiencia, utilizado un anillo de compromiso.

Además, se ha observado que en la mayoría de las ocasiones en las que los modelos se mostraban vistiendo anillos, tatuajes, brazaletes, aretes y collares, los modelos eran visiblemente jóvenes, represetnados en edades que oscilan entre los 19 y 25 años. Accesorios como relojes, lentes, y manbags, eran típicamente vestidos por hombres de una edad mayor. Estos resultados sugieren que el uso de joyería y tatuajes es una moda propia de una generación de hombres más jóvenes.

En cuanto a la posible identificación de la sexualidad de los sujetos analizados, en el $88 \%$ de los casos ha sido "Imposible inferir la sexualidad", seguido por una "Sugerencia de heterosexualidad" con un 7\% y una "Sugerencia de heterosexualidad con contacto" con un $3 \%$. Ninguno de los sujetos han sido catalogados bajo "Aparentemente homosexual" y "Homosexual con contacto".

Tomando en cuenta la literatura estudiada y comentada en capítulos anteriores, los resultados de esta variable han resultado muy interesantes, al confirmar, tal como lo han especificado diversas investigaciones en el pasado, que la publicidad actual se representa frecuentemente bajo una luz "desconocida" o "ambigua" cuando se trata de la sexualidad de los sujetos. Dentro de los anuncios analizados, ha sido imposible inferir de manera certera la orientación sexual de los sujetos en 121 anuncios, salvo por 16 anuncios, de los cuales 13 sugerían heterosexualidad y tres sugerían homosexualidad pero nunca de una manera explícita, es decir, mostrando contacto o lenguaje corporal entendido como sexual o sugerente entre dos o más sujetos masculinos, o bien, mediante el empleo de palabras o imágenes que hicieran referencia a este colectivo.

De estos resultados se puede inferir que las revistas actuales occidentales dirigidas al público masculino dejan al gusto del consumidor la lectura, en términos de orientación sexual, de las imágenes contenidas en sus páginas. En otras palabras, las revistas no se decantan explícitamente por una orientación sexual a través de sus representaciones, 
sino que se abstienen de hacerlo, al mantener sus representaciones bajo una luz ambigua en cuanto a la sexualidad de sus sujetos y dejando que los consumidores hagan la lectura que prefieran de las imágenes publicadas.

En el análisis de la importancia de los sujetos analizados, el 76\% se ubicó en un "Rol principal", el 21\% en un "Rol secundario" y el 12\% como "Extra". En la mayoría de las ocasiones en las que el sujeto masculino no se ha mostrado desempeñando el rol principal del anuncio, ha sido porque se ha mostrado a la lejanía, casi siempre en espacios rurales y abiertos grandes, que le han quitado protagonismo. Sin embargo, aunque en estas ocasiones no ha sido el protagonista del anuncio, casi siempre se le ha mostrado solo, inmerso en la naturaleza y sus magnitudes.

En cuanto al rol asumido por los sujetos analizados, el $29 \%$ ha caído dentro de la categoría "Hombre consciente de su estilo/modelo", el 17\% dentro de "Consumidor", y el $12 \%$ dentro de "Otro" y "Hombre al aire libre". Los resultados de esta variable sustentan y refuerzan la lectura hecha para la variable de "Indumentaria" en apartados pasados. Dentro de esta variable se ha comentado que la vestimenta mostrada por los sujetos nunca ha sido aquella propia de un hombre trabajador, sino aquella de un hombre interesado en el disfrute y el placer. Por lo que, el hecho de que el "Rol asumido" por estos sujetos casi siempre haya sido el de un hombre consciente de su estilo y su apariencia física, o el de un hombre consumidor, viajero, o al aire libre, sustenta la noción de que en la publicidad actual se le da mayor protagonismo a imágenes que comuniquen valores hedonistas y egoístas, por encima de valores colectivos que promuevan las relaciones interpersonales ya sea a nivel familiar o laboral.

En el análisis de la actitud o cualidad principal que presentaban los sujetos dentro de los anuncios analizados, el $31 \%$ se mostraba "Serio", seguido por $22 \%$ que se mostraban "Alegres/satisfechos" y $21 \%$ que mostraban cualidades propias de un "Seductor".

Tal como se ha explicado en el apartado que expone la metodología y la muestra seleccionadas para el estudio, la variable de "Seriedad" ha sido añadida una vez iniciado el estudio, al determinar necesaria su inclusión debido a la gran incidencia de modelos 
que se mostraban con una actitud seria, solemne, incluso fría, y a la falta de una variable que los englobara.

El hecho de que las actitudes y cualidades que se pueden interpretar como propias de un seductor y de una persona seria hayan sido las que han dominado la representación de los sujetos analizados, abre una interesante línea de discusión en cuanto a la perdurabilidad de estereotipos culturales que mantienen que los sentimientos y la vulnerabilidad no son actitudes propias de un hombre y que, en todo caso, es mejor que sean reprimidas y sustituidas por actitudes frías y poco introspectivas.

Además, el resultado de esta variable también refuerza la noción de que los hombres en la publicidad actual muestran muy poco interés por el desarrollo de relaciones interpersonales de calidad al ser mostrados en actitudes poco sociales, a través de imágenes que invitan más a la compostura y a la discreción en lugar de a la convivencia y al desenfado.

La actitud de alegría ha sido también una de las actitudes más recurrentes en la muestra analizada. Sin embargo, resulta relevante comentar que en la mayoría de los casos, cuando los sujetos se mostraban alegres, no era gracias al desarrollo o establecimiento de relaciones interpersonales, sino que su alegría era enteramente provocada por el producto consumido. Es decir, aquellos anuncios en donde el modelo se muestra alegre mientras posa con productos de la marca anunciada.

En relación con el espacio predominante en el que se encontraban representados los modelos, el $23 \%$ se ubicó en un paisaje "Urbano", el $21 \%$ en un espacio "Rural, naturaleza", y el $17 \%$ en "Otro" bajo la categoría de espacio interior. Ninguno de los anuncios analizados mostraban al sujeto analizado dentro de una "Tienda o gran superficie".

En el análisis del espacio donde se muestran los sujetos masculinos ha sido interesante observar la prevalencia de dos espacios exteriores que, de cierta forma, podrían ser considerados opuestos: el espacio urbano y el espacio rural. 
Por una parte, muchos de los sujetos se mostraban dentro de una ciudad, nunca dentro de oficinas u espacios de trabajo, sino más bien en los lugares sofisticados y atractivos que puede llegar a ofrecer una metrópoli, y por el contrario, muchos otros se mostraban al aire libre, en la naturaleza y en la inmensidad que ésta ofrece. Sin embargo, un común denominador para estos dos espacios es que, independientemente si era en la ciudad o en la naturaleza, los sujetos se mostraban bajo una luz antropocéntrica en donde no perdían su protagonismo e importancia, independientemente del lugar donde se encontraran. Es decir, los beneficios tanto de la ciudad como de la naturaleza, giraban entorno al sujeto, y no al contrario; estos beneficios estaban a la merced del disfrute del sujeto masculino, en lugar del sujeto masculino estar sumergido en los beneficios de estos entornos, desconectándose de sí y permitiéndose una inmersión total y un disfrute honesto de estos espacios.

Dentro de la segunda fase del análisis descriptivo de los sujetos, se establecieron siete variables adaptadas del trabajo realizado por Erving Goffman. La primera de estas categorías se enfocaba en analizar el acompañamiento de los sujetos, resultando en un $68 \%$ que se encontraban "Solos", un $10 \%$ representados con "Uno o más hombres" y otro $10 \%$ representados con "Una o más mujeres".

Los resultados obtenidos en esta variable sustentan, una vez más, la gran importancia que la publicidad actual dirigida a hombres le ha otorgado a valores narcisistas y del yo. En la gran mayoría de los anuncios los sujetos se han encontrado representados por sí solos, enfocándose en su disfrute y entretenimiento.

En línea con lo que se ha comentado en los resultados obtenidos para la variable de actitud, en aquellos casos en los que el sujeto masculino se ha representado acompañado, por hombres, por mujeres, o por ambos, en contrario de tal vez se esperaría, el sujeto se sigue mostrando serio en lugar de alegre, aún cuando está rodeado de otras personas. La actitud de alegría casi siempre se asocia con productos en lugar de con personas. Esto se debe principalmente a que, incluso cuando los sujetos masculinos están acompañados, el valor que predomina en el anuncio es el de la 
estética, la elegancia y el sentido artístico, pasando los valores colectivos de amistad, familia y convivencia a un segundo plano.

Mediante la segunda variable adaptada del estudio realizado por Goffman se analizó la posición del sujeto, resultando en un 42\% posando "Parado", un 20\% posando "Sentado" y un 20\% para los que fue "Imposible Determinar" la posición.

En cuanto a esta variable es interesante destacar la prevalencia de sujetos que se mostraban parados, pero también, de sujetos que se encontraban en posiciones englobadas bajo la categoría "Otro", en donde, mayoritariamente, se incluyeron sujetos que se encontraban realizando algún tipo de actividad física, generalmente asociada a deportes y también al manejo de motocicletas. En cuanto al tamaño relativo del sujeto protagonista en comparación con los demás sujetos presentes en el anuncio, se ha encontrado que en el $69 \%$ de las veces esta variable "No Aplicaba" al anuncio, en el $22 \%$ de las ocasiones se encontraban a la "Misma altura", y en el 4\% los "Hombre(s)" tenían un tamaño relativo mayor. Ningún anuncio ha mostrado a "Niños" en un tamaño relativo mayor a otros sujetos o en un rol dominante.

Dentro de esta variable fue muy interesante descubrir que cuando un sujeto masculino se representaba acompañado por una mujer, tenían siempre el mismo tamaño relativo, o incluso, las mujeres se mostraban en un nivel más alto que los hombres. Esto difiere completamente de los resultados obtenidos por Goffman en el pasado (1979), en donde el hombre típicamente estaba retratado en una posición de poder, con un tamaño relativo mayor.

Esto va en línea con algunas ideas planteas por autores como Crewe 2002, quien sugiere que actualmente nos encontramos en una época en donde se está viendo y exigiendo una igualdad entre los hombres y las mujeres en la representación publicitaria, en donde ambos tienen acceso a la posición tanto de productor como de consumidor, y en donde es ya muy poco común ver a las mujeres representadas en papeles subordinados o denigrantes con respecto a los hombres. 
En el análisis de la cantidad de piel expuesta de los sujetos, se ha encontrado que el $88 \%$ estaba "Totalmente vestido", mientras que el $7 \%$ tenía la "Parte superior del cuerpo parcialmente expuesta", el 2\% mostraba "Desnudez o sugerencia de desnudez" y para otro $2 \%$ fue "Imposible determinar".

Contrario a lo que mucha de la literatura ha planteado en el pasado con respecto a la creciente exposición erótica del cuerpo masculino en la publicidad moderna, en este estudio se ha encontrado que en el $88 \%$ de los anuncios analizados se representaban a los hombres completamente vestidos, mientras que solo un $2 \%$ planteaba una sugerencia de desnudez. Sin embargo, es cierto, que aunque vestidos, un $21 \%$ del total se mostraba con una actitud seductora y sugerente. Es decir, en la publicidad actual se podría considerar que se objetiviza al hombre, pero no mediante técnicas como la exposición erótica de su cuerpo, sino mediante otras herramientas tales como la mirada y el lenguaje corporal.

En cuanto al encuadre de la fotografía, en el $82 \%$ de los anuncios se muestra al sujeto completo, mientras que en un $15 \%$ se muestra solo el rostro, y en el restante $3 \%$ se encuadran solamente partes del cuerpo. En ninguna ocasión el encuadre ha agrupado "Varias" de las categorías pasadas o ha sido algún "Otro" encuadre que no esté englobado en las categorías antes planteadas.

En línea con lo mencionado anteriormente y tomando en cuenta los resultados aquí expuestos, se refuerza la noción de que la publicidad actual recurre a otras herramientas para representar al hombre en actitud seductora y sugerente, alejadas de la típica técnica de exponer el cuerpo desnudo. Dentro de las imágenes que se codificaron bajo "Solo el rostro" en esta variable, la gran mayoría, comunicaban a través de lenguaje verbal y de la mirada, una actitud sugerente y provocadora, sin necesidad incluso de recurrir a mostrar el cuerpo, ya sea desnudo o completamente vestido.

Evaluando la prevalencia del auto-contacto por parte de los sujetos, se ha encontrado que un $93 \%$ no estaban involucrados en esta práctica, mientras que un $7 \%$ si lo estaban. 
Aunque $7 \%$ es un porcentaje bajo, la mera existencia de esta técnica sugiere que si, en efecto, existe una tendencia creciente en el uso de recursos gráficos en la publicidad dirigida a hombres que durante años han sido empleados en anuncios mostrando mujeres, y que han sido considerados como meras formas de objetivizar y sexualizar a los sujetos que las practican.

Tal como lo estableció Goffman (1979) en su estudio, el auto-contacto es una forma de convertir al cuerpo del sujeto que la practica en un producto precioso y deseable, que merece ser acariciado y trazado con las manos. Resulta de suma relevancia que esta técnica que se considera que ha sido utilizada para objetivar el cuerpo de las mujeres durante años, sea ahora empleada también en los hombres.

Analizando el uso de la mirada, se ha encontrado que en el $42 \%$ de los anuncios "La mirada estaba desentendida de la audiencia", en el 38\% "La mirada estaba dirigida a la audiencia" y en el 15\% de los anuncios la mirada estaba fijada de alguna "Otra" manera no englobada en las categorías establecidas.

Las últimas dos materias de análisis englobadas bajo el denominador de "Nuevas variables" están conformadas por "Expresión Diversa" y "Metrosexualidad". En cuanto a la presencia de sujetos que pudiesen ser catalogados como de "Expresión Diversa" se ha encontrado que en el $93 \%$ de los casos "No" se podía catalogar a los sujetos de esta manera, mientras que en un $7 \%$ de los casos si se encontraban bajo esta categoría.

Por último, en cuanto a la presencia de sujetos que pudiesen ser catalogados bajo el arquetipo de "Metrosexual" se ha encontrado que en el $64 \%$ de los casos "Si" se podía catalogar a los sujetos de esta manera, mientras que en un $36 \%$ de los casos no se podía considerar a los sujetos como adscritos a este tipo de masculinidad. Los porcentajes globales y los totales para cada categoría dentro de esta variable se encuentran representados en las Figuras 45 y 46.

\section{CONCLUSIÓN}

Los resultados clave que ha arrojado este estudio, producto del método propuesto y análisis realizado, se delinean a continuación a manera de conclusiones: 
a. La publicidad actual dirigida a hombres favorece la exhibición de valores del yo -asociados a características narcisistas y egocentristas - reflejados en elementos gráficos de su discurso publicitario y en la manera en la que representan a los sujetos masculinos que emplean, relegando los valores colectivos -en los cuales priman la convivencia y el establecimiento de relaciones interpersonales - a un segundo plano.

b. La actitud dominante en la representación de los sujetos analizados es aquella de un hombre serio, que no necesita de compañía, que muestra pocos o incluso nulos sentimientos, y un bajo nivel de interés en el desarrollo y mantenimiento de relaciones interpersonales.

c. Si bien la publicidad actual es más propensa a mostrar expresiones diversas de género y de masculinidad, es clara la prevalencia de un prototipo de hombre ideal que domina el discurso publicitario dirigido al público masculino actual: un hombre tonificado, joven, con cabello claro, elegante, con rasgos occidentales y que goza de un alto nivel adquisitivo.

d. El hombre contemporáneo ha comenzado a ocupar un terreno que antes era exclusivo de las mujeres, el cual consiste en el desempeño de tareas y prácticas dirigidas al cuidado, mantenimiento y mejora del aspecto físico. Como producto de esta adopción de prácticas "femeninas", el sujeto masculino ha pasado a ocupar la posición de "observado" mediante el cual ya no teme, y más bien busca activamente, la mirada indiferenciada del otro.

e. La publicidad actual recurre todavía a elementos gráficos que funcionan porque se valen de la vigencia de estereotipos culturales enraizados en nociones que distinguen de manera clara y típica a la feminidad de la masculinidad, en concreto: el color azul y el negro -asociados al poder y la templanza-propios de los hombres y la masculinidad, mientras que el color rosa -asociado a la suavidad y a la delicadeza-es propio de las mujeres y su feminidad.

f. Si bien es cierto que la sexualización y objetivación del sujeto masculino es una tendencia creciente en la imagen publicitaria, ésta no se lleva a cabo mediante técnicas de exposición de piel y sugerencia de desnudez. Al contrario, se hace 
mediante técnicas más sutiles, como el lenguaje corporal, la mirada, el encuadre de la fotografía y el auto-contacto.

g. El hecho de que los hombres y las mujeres ahora puedan ocupar los roles tanto de productor como consumidor ha llevado a una creciente igualdad de género en el discurso publicitario, la cual se ve reflejada en la obsolescencia de composiciones en donde el sujeto masculino toma roles dominantes o tamaños relativos mayores. En la publicidad actual, cuando están retratados juntos, los hombres y mujeres tienen el mismo tamaño y son ubicados a la misma altura.

h. Las revistas contemporáneas dirigidas a hombres se abstienen de exponer de manera explícita su posición en cuanto a cuestiones de orientación sexual, al representar a los sujetos masculinos bajo una luz ambigua, haciendo prácticamente imposible una inferencia clara y definitiva de la sexualidad de los sujetos, y permitiendo así que cada consumidor le dé la lectura que más le guste y convenga a las imágenes publicitarias.

i. Si bien podría resultar radical afirmar que la metrosexualidad es actualmente la norma en cuanto a la masculinidad, en definitiva, ha sido el arquetipo que ha dominado las representaciones de sujetos masculinos analizadas en este estudio.

Los resultados que categorizan los tipos de productos publicitados en los anuncios de la muestra, corroboran la hipótesis inicial de este trabajo, ya que han reflejado que la mayoría de los anuncios están destinados a vender productos que tienen una asociación directa con la moda, el estilo, la estética, y la mejora del aspecto físico de las personas, además de que lo hacen apelando a valores mayoritariamente narcisistas, dejando de lado aquellos valores que apelan a la colectividad y al altruismo de las personas.

La primera hipótesis complementaria del estudio se embarcaba en reforzar la hipótesis inicial, al formular que el estereotipo del hombre trabajador y líder de familia ha sido sustituido por un hombre interesado en sí mismo enfocado en actividades que le den placer y disfrute, con poco interés en el desarrollo de relaciones interpersonales de calidad. 
La variables que han servido para corroborar ésta hipótesis, han sido la que se embarcaron en analizar las actitudes y cualidades mostradas por los sujetos analizados. Dentro de esta variable se ha encontrado que el $31 \%$ de los sujetos se mostraban serios, solemnes, fríos, sin exhibir ningún tipo de sentimiento o actitud, simplemente posando con una actitud fría, impenetrable y reservada, aquella que comunica la presencia nula de un interés por la convivencia, o por el establecimiento de vínculos ni con otros sujetos ni con el espectador, pero cabe destacar que, en la mayoría de los casos, estos modelos se mostraban alegres por sí solos, es decir, su alegría pocas veces derivaba de la convivencia y de los sentimientos positivos que pueden surgir del fomento $y$ fortalecimiento de las relaciones interpersonales, sino que derivaba de actividades desarrolladas de manera individual.

El cromatismo es un aspecto muy relevante dentro de la configuración del mensaje publicitario debido a la gran carga simbólica y psicológica que tienen los colores en el espectador. Históricamente, ha sido una herramienta empleada por mercadólogos y publicistas en la consolidación de sus discursos publicitarios.

Todos estos elementos convergen de una manera tal, que nos permite corroborar la primera hipótesis complementaria planteada al inicio del estudio, la cual especulaba en la transición del estereotipo del hombre trabajador y líder de familia a aquel enfocado en sí mismo y su disfrute, con poco o incluso nulo interés en las relaciones interpersonales.

La segunda hipótesis complementaria planteada al inicio del estudio, ha supuesto un cambio en el arquetipo de masculinidad vigente en la sociedad contemporánea, con respecto a arquetipos que han estado vigentes en el pasado. A grandes rasgos, se teorizaba que este nuevo arquetipo, a diferencia de los otros, mostraba un creciente interés por prácticas y rutinas anteriormente asociadas a las mujeres y a la feminidad, y también un cambio en la posición que típicamente ha ocupado el hombre dentro de la relación "observador" y "observado".

En el presente estudio, la categoría establecida por Goffman (1979) fue retomada y modificada para explorar la relación que mantienen los sujetos masculinos con la mirada en la muestra analizada. Esta variable reflejó que el $42 \%$ de los sujetos mostraban una 
mirada que estaba desentendida de la audiencia, si se lleva a cabo un análisis de estos porcentajes, teniendo como base que el $21 \%$ de los sujetos se mostraban con cualidades propias de un seductor, y que el $68 \%$ se retrataba solo, se puede hacer una lectura que sustenta la noción de que ha habido un cambio en la posición que ocupa el sujeto masculino en el sistema "observado" y "observador". En los anuncios analizados en este estudio, la mayoría de los hombres se mostraban mayoritariamente con cuerpo completo, solos, y, en la mayor parte de los casos en una posición pasiva, en donde su mirada estaba desentendida de la audiencia, sin dejar de mostrarse seductores a través de su lenguaje corporal.

La última hipótesis complementaria establecida al inicio del estudio exploraba la suposición de que las representaciones masculinas utilizadas en la publicidad actualmente se asemejan cada vez más al tipo de representaciones que se han utilizado históricamente para dirigirse a mujeres; aquellas repletas de ideales inasequibles y representaciones utópicas. Si bien el presente estudio cuenta con varias limitantes que permitan llevar a cabo una conclusión definitiva en cuanto a esta formulación, ya que se necesitaría indagar en la correlación que existe entre la publicidad dirigida al público masculino y los niveles de autoestima e inconformidad de los sujetos a los que se dirige, o bien, los aumentos en la cantidad de cirugías plásticas y rutinas de embellecimiento, algunos resultados nos pueden proveer un vistazo general de esta problemática.

En la variable que observaba la constitución física de los sujetos implementados en los anuncios, se ha encontrado que el 53\% tenía una complexión que entraba dentro de la categoría de delgado, mientras que un $20 \%$ se catalogó como fuerte/tonificado y solamente un $4 \%$ se categorizó como gordo o redondo. En cuanto a los rasgos étnicos de los sujetos, se ha encontrado que el $73 \%$ mostraban rasgos considerados como "occidentales", mientras que en un $18 \%$ se agrupaban sujetos con rasgos afroamericanos, latinos, y otros (asiáticos, árabes, etc). Por otra parte, se ha encontrado que el $85 \%$ de los sujetos tenían cabello rubio o moreno, y el $66 \%$ se encontraban dentro de rangos de edad que consideran al ser humano como una persona joven. 
Este conjunto de resultados, aunque se queda corto en cuanto al nivel de análisis que se requiere para intentar corroborar o desmentir esta tercera hipótesis complementaria, sí que permite encontrar una serie de patrones en la representación analizada; los sujetos observados muestran mayoritariamente una complexión delgada y tonificada, se muestran rubios o morenos pero casi siempre con rasgos considerados occidentales, y son mayoritariamente jóvenes.

Por otra parte, en el apartado de la metrosexualidad, se encontró que el $64 \%$ de los sujetos analizados mostraban características que se han establecido en la literatura como rasgos típicos de este nuevo arquetipo es importante rescatar que la forma en la que ha sido evaluada la presencia de este arquetipo en la muestra seleccionada ha sido muy limitada y generalizada, y su propio estudio requeriría un planteamiento y un análisis mucho más profundos. Sin embargo, basándonos en la premisa de que el metrosexual puede ser definido como un hombre con dinero para gastar, que vive en o cerca de una metrópolis ya que le gusta disfrutar de sus comodidades, que le resulta irrelevante revelar su orientación sexual, que tiene un gran interés por la moda y por el cuidado de su apariencia física, y que muestra altos niveles de narcisismo y egocentrismo al tenerse a él mismo como objeto de amor y de placer (Simpson, 2002) se ha encontrado al $64 \%$ de los sujetos como aptos para caer dentro de esta categoría, basándonos en los resultados que han arrojado en relación a otras categorías y variables bajo las cuales se analizaron.

\section{REFERENCIAS BIBLIOGRÁFICAS}

Alexander, M. (2003). Stylish Hard Bodies: Branded Masculinity. Men's Health Magazine. Sociological Perspectives, 46(4), 535-554.

https://doi.org/10.1525/sop.2003.46.4.535

Anderson, E. (2006). Orthodox and Inclusive Masculinity: Competing Masculinities Among Heterosexual Men in a Feminized Terrain. Sociological Perspectives, 48(3), 337355. https://doi.org/10.1525/sop.2005.48.3.337 
Benwell, B. (2004). Ironic discourse: Evasive masculinity in men's lifestyle magazines. Men and Masculinities, 7, 3-21. https://doi.org/10.1177/1097184X03257438

Berg, B. y Lune, H. (2012). Qualitative research methods for the social sciences (8a ed.). Upper Saddle River, NJ: Pearson.

Berkery, E., Morley, M. y Tiernan, S. (2013). Beyond gender role stereotypes and requisite managerial characteristics: from communal to androgynous, the changing views of women. Gender in Management: An International Journal, 28(5), 278-298. Recuperado de https://bit.ly/2XXjKZz

Boni, F. (2002). Framing media masculinities. European Journal of Communication, 17, 465-478. https://doi.org/10.1177/02673231020170040401

Canape, C. (1985). Refashioning the male marketplace. Marketing \& Media Decisions, 20, 84-88. https://doi.org/10.1177/019685999001400106

Conde Nast Media Kit. (2017). [online] Recuperado de https://bit.ly/2KxBBDn

Crewe, B. (2002). Consuming men: Producing loaded. En S. Miles, A. Anderson,A. y K. Meethan (Eds.), The changing consumer: Markets and meanings (pp. 41-55). New York: Routledge.

Cutler, K. (2007). Multiple masculinities? A content analysis of men in the print media. Master of Sociology. Washington State University.

Dotso, E. W. (1999). Behold the Man: The Hype and Selling of Male Beauty in Media Culture. New York: The Haworth Press.

Emig, R. (2000). Queering the Straights: Straightening Queers: Commodified Sexualities and Hegemonic Masculinity. En R. West y F. Lay (Eds.), Subverting Masculinity (pp. 207226). Amsterdam: Editions Rodopi B.V.

Flocker, M. (2003). The Metrosexual Guide to Style: A Handbook for the Modern Man. Boston, MA: Da Capo Press. 
Ford, J. B., Voli, P. K., Honeycutt Jr, E. D. y Casey, S. L. (1998). Gender role portrayals in Japanese advertising: A magazine content analysis. Journal of Advertising, 27(1), 113124. https://10.1080/00913367.1998.10673546

Gardiner, J. K. (2002). Masculinity Studies \& Feminist Theory: New Directions. New York: Columbia University Press.

Gentry, J. y Harrison, R. (2010). Is advertising a barrier to male movement toward gender change?, Marketing Theory, 10(1), 74-96. https://10.1177/1470593109355246

Goffman, E. (1979). Gender advertisements. Cambridge, MA: Harvard University Press. Gotting, P. (11 de marzo de 2003). Rise of the metrosexual. The Age. Recuperado de https://bit.ly/3oamdL3

Hall, S. (1997). The Work of Representation. En S. Hall (Ed.), Representation: Cultural Representations and Signifying Practices (pp. 13-74). London, UK: Sage.

Hood, M. (2003). Straight Style; 'Metrosexuals' Prove that Gay Men Have No Monopoly on Looking Good. The Columbus Dispatch. En T. Reichart y J. Lambiase (Eds.), Sex in Advertising: Perspectives on the Erotic Appeal. London: Routledge

Jackson, P., Stevenso, N. y Brooks, K. (2001). Making Sense of Men's Magazines. Cambridge, MA: Polity.

Kacen, J. J. (2000). Girl power and boy nature: the past, present, and paradisal future of consumer gender identity. Marketing Intelligence \& Planning, 18(6/7), 345-355. https://doi.org/10.1108/02634500010348932

Kimmel, M. S. (2005). The Gender of Desire. Albany, NY: State University of New York Press.

Knutson, M. y Waldner, M. (2017). Reshaping the man in the mirror: The effects of challenging stereotypical male portrayals in advertising (Bachelor of Science thesis, Stockholm School of Economics). 
Lay, T. (2018). The Construction of Gender in Contemporary Magazine Advertisements. The University of Ottawa, Research Paper. Recuperado de https://ruor.uottawa.ca/handle/10393/36940

Leader, C. (2019). Dadvertising: Representations of fatherhood in Procter \& Gamble's Tide commercials. Communication, Culture \& Critique, 12, 72-89.

Larsen, P. (4 de enero de 2004). Make Room for the Metrosexual. Sarasota HeraldTribune.

Leiss, W., Kilne, S., Jhally, S. y Boterill, J. (2005). Social communication in Advertising: Consumption in the Mediated Marketplace (3a ed.). New York: Routledge.

Lempert, P. (2004), Metrosexuals at the market, Progressive Grocer, 83(12) 10-26. Recuperado de https://bit.ly/2LOCVCp

Mager, J. y Helgeson, J. G. (2011). Fifty years of advertising images: Some changing perspectives on role portrayals along with enduring consistencies. Sex Roles, 64(3-4), 238-252. Recuperado de https://bit.ly/3o6jjXj

Mason, M. (2003). A Content Analysis of the Portrayal of Men in Advertising: Gentleman's Quarterly 1985-2000. Rochester Institute of Technology.

Medina, A. (2011). La imagen del niño en los spots televisivos. Doctorado. Universidad de Málaga.

Méndiz, A. (2005). La juventud en la publicidad. En C. Naval y Ch. Sádaba (Coords.), Jóvenes y Medios de Comunicación. Revista de Estudios de juventud, 68, 104-115. Recuperado de https://bit.ly/39Vytdg

Messner, M. (2000). Becoming 100\% Straight. En M. Baca Zinn, P. Hondagneu-Sotelo y M. A. Messner (Eds.), Gender Through the Prism of Difference. Needham Heights, MA: Allyn \& Bacon.

Miller, T. (2005). A Metrosexual Eye on the Queer Guy. Journal of Lesbian and Gay Studies, 11(1), 112-117. https://:10.1215/10642684-11-1-112 
Mirchandani, R. P. (22 de abril de 2004). Mano a Mano; Metrosexuals are the Modem Girl's 'Mister Right'. Boston Herald.

Nixon, S. (1996) Hard looks: Masculinities, spectatorship and contemporary consumption. New York: St Martin's Press.

Peitsch, E. (2004). Making over masculinity: the metrosexual and the rise of the styleconscious male (Graduate Thesis). McGill University, Montreal. Recuperado de https://escholarship.mcgill.ca/concern/theses/m326m227s

Pringle, R. (2005). Masculinities, sport, and power: A critical comparison of Gramscian and Foucauldian inspired theoretical tools. Journal of Sport and Social Issues, 29, 256278. https://doi.org/10.1177/0193723505276228

Riff, D., Lacy, S. y Fico, F. (2014). Analyzing media messages: Using quantitative content analysis in research. London: Routledge.

Rohlinger, D. (2002). Eroticizing Men: Cultural Influences on Advertising and Male Objectification. Sex Roles, 46(3/4): 61-74. https://10.1023/A:1016575909173

Salzman, M., Matathia, I. y O’Reilly, A. (2005), The Future of Men. Basingstoke: Palgrave Macmillan

Schroeder, J. y Zwick, D. (2004). Mirrors of Masculinity: Representation and Identity in Advertising Images. Consumption Markets \& Culture, 7(1), 21-52. https://doi.org/10.1080/1025386042000212383

Screti, F. (2019). Carne, carbón, y cojones. La representación de la masculinidad en anuncios suizos contemporáneos: El caso de Bell. Discurso \& Sociedad, 4, 765-807.

Segal, B. y Podoshen, J. S. (2013), An examination of materialism, conspicuous consumption and gender differences. International Journal of Consumer Studies, 37(2), 189-198. https://doi.org/10.1111/j.1470-6431.2012.01099.x

Simpson, M (2004). Everyday Sociology Blog: The Metrosexual: Men and Beauty. everydaysociologyblog.com. Recuperado de https://bit.ly/3sKJ5E2 
Simpson, M. (2002). Meet the metrosexual: he's well dressed, narcissistic and bunobsessed. But don't call him gay. Salon. Recuperado de https://bit.ly/3bXNbDa

Simpson, M. (1994). Here Come the Mirror Men: Metrosexual Men. The Independent.

St. John, W. (22 de junio de 2003). Metrosexuals Come Out. The New York Times. Recuperado de https://cutt.ly/jR1zXPH

Taylor, L. D. (2005). All for him: Articles about sex in American lad magazines. Sex Roles, 52, 153-163. Recuperado de https://bit.ly/3p2y1jn

Vigorito, A. y Curry, T. J. (1998). Marketing Masculinity: Gender Identity and Popular Magazines. Sex Roles, 39(1/2): 135-52. Recuperado de https://bit.ly/3iveupu

Vranica, S. (2003). Marketing \& Media-Advertising: Stereotypes of Women Persist in Ads; Bikinis Still Sell the Suds, As Masculine Views Reign; Agency Gender Gap Blamed. Wall Street Journal, 17, 4.

Wolin, L. D. (2003). Gender issues in Advertising-An oversight synthesis of research: 1970-2002. Journal of Advertising Research, 43(1), 111-129. https://10.1017/S0021849903030125 


\section{ANEXOS}

Tabla 1. Criterios de análisis de los anuncios

\begin{tabular}{|c|c|c|}
\hline \multirow{3}{*}{ Identificación } & Tipología & Criterio \\
\hline & Producto & $\begin{array}{l}\text { Cosmética y belleza personal } \\
\text { Bebidas alcohólicas } \\
\text { Textil, vestimenta y calzado. } \\
\text { Higiene personal } \\
\text { Joyería y accesorios } \\
\text { Automóviles y motocicletas } \\
\text { Viajes, turismo y transporte de personas } \\
\text { Productos tecnológicos relacionados con el } \\
\text { trabajo } \\
\text { Tecnología } \\
\text { Alimentación y bebida } \\
\text { Videojuegos } \\
\text { Electrodomésticos, menaje y hogar } \\
\text { Cigarros } \\
\text { Servicios financieros, seguros y bancos } \\
\text { Telecomunicaciones, telefonía y mensajería } \\
\text { Equipo de ejercicio } \\
\text { Medicinas y salud } \\
\text { Óptica } \\
\text { Entretenimiento } \\
\text { Varios/otros }\end{array}$ \\
\hline & Marca & \\
\hline Análisis técnico & $\begin{array}{c}\text { Color } \\
\text { predominante }\end{array}$ & $\begin{array}{l}\text { Rojo } \\
\text { Azul } \\
\text { Verde } \\
\text { Amarillo } \\
\text { Gris } \\
\text { Naranja } \\
\text { Marrón } \\
\text { Violeta } \\
\text { Blanco } \\
\text { Negro } \\
\text { Rosa } \\
\text { Ninguno } \\
\text { Otro }\end{array}$ \\
\hline
\end{tabular}




\begin{tabular}{|c|c|c|}
\hline & $\begin{array}{c}\text { Valor asociado al } \\
\text { producto }\end{array}$ & $\begin{array}{l}\text { Amistad, convivencia } \\
\text { Belleza, atracción, seducción } \\
\text { Calidad } \\
\text { Colectividad, pertenencia al grupo } \\
\text { Comodidad, confort, facilidad de uso } \\
\text { Competitividad } \\
\text { Comprensión, ternura } \\
\text { Economía, barato } \\
\text { Efectividad, utilidad } \\
\text { Energía, fuerza, vitalidad, coraje } \\
\text { Evasión, independencia, libertad } \\
\text { Éxito } \\
\text { Familia } \\
\text { Juventud } \\
\text { Natural, naturaleza } \\
\text { Novedad y variedad } \\
\text { Placer, disfrute, relajación } \\
\text { Poder } \\
\text { Respeto a los mayores, madurez, tradición } \\
\text { Sabiduría, afán de saber } \\
\text { Salud } \\
\text { Seguridad y protección } \\
\text { Sexo, sensualidad } \\
\text { Solidaridad, ayuda } \\
\text { Tecnología } \\
\text { Ámbito laboral } \\
\text { Trabajo, esfuerzo } \\
\text { Elegancia, estilo,estético, artístico }\end{array}$ \\
\hline \multirow{3}{*}{$\begin{array}{l}\text { Análisis descriptivo } \\
\text { Representación del } \\
\text { sujeto masculino }\end{array}$} & Edad & $\begin{array}{l}\text { Primera infancia } \\
\text { Segunda infancia } \\
\text { Adolescencia } \\
\text { Primera juventud } \\
\text { Segunda juventud } \\
\text { Primera edad adulta } \\
\text { Segunda edad adulta } \\
\text { Vejez } \\
\text { Imposible determinar }\end{array}$ \\
\hline & Color de cabello & $\begin{array}{l}\text { Rubio } \\
\text { Moreno } \\
\text { Pelirrojo } \\
\text { Otro/imposible determinar }\end{array}$ \\
\hline & Rasgos étnicos & $\begin{array}{l}\text { Occidental } \\
\text { Afro-americano } \\
\text { Latino/hispánico } \\
\text { Otro } \\
\text { Incapaz de determinar }\end{array}$ \\
\hline
\end{tabular}

RAE-IC, Revista de la Asociación Española de Investigación de la Comunicación vol. 8, núm. 16 (2021), 356-398 


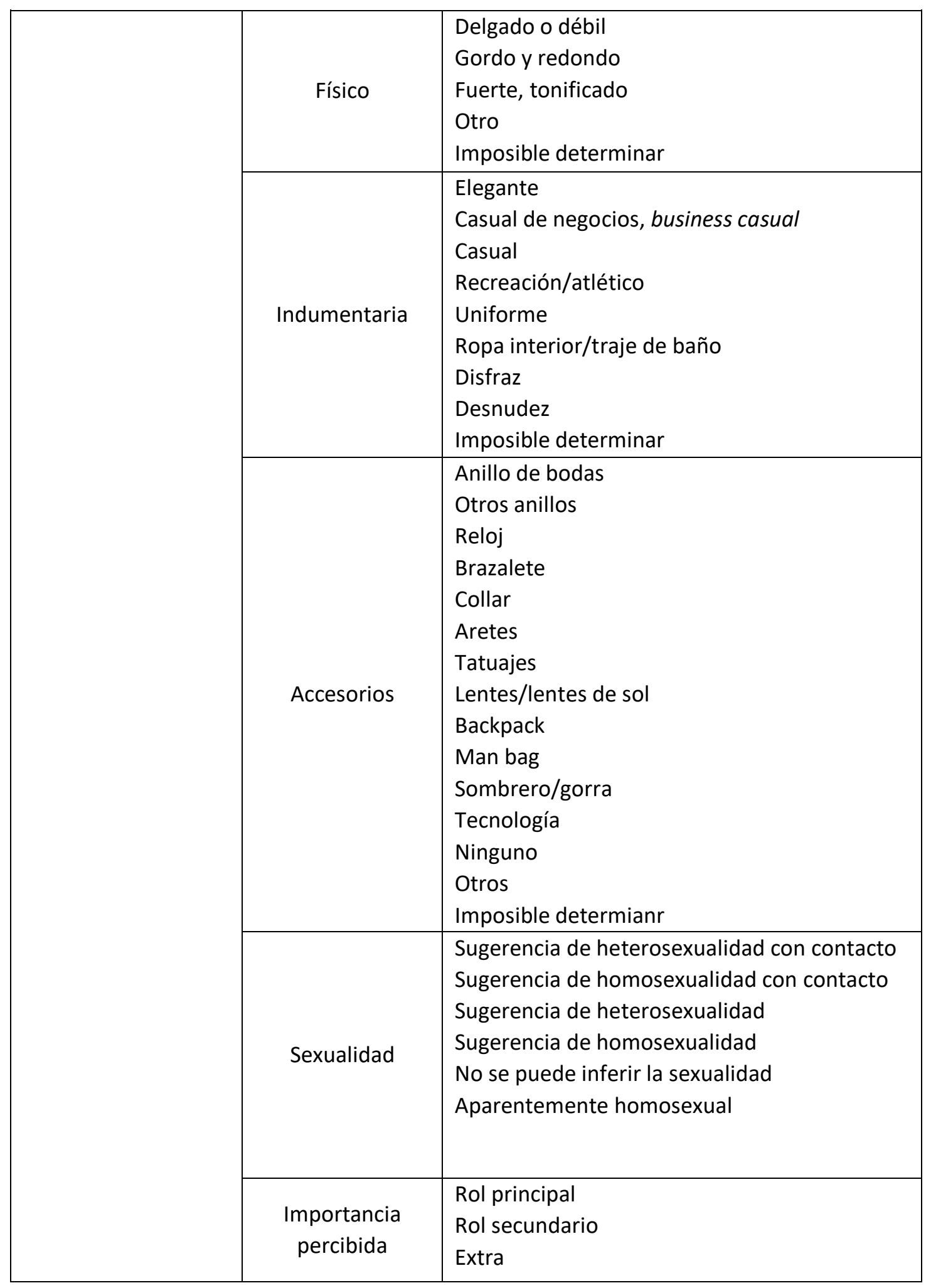




\begin{tabular}{|c|c|c|}
\hline & Rol que asume & $\begin{array}{l}\text { Hombre deportista/atleta } \\
\text { Hombre al aire libre } \\
\text { Hombre de familia } \\
\text { Marido/amante } \\
\text { Hombre en el trabajo } \\
\text { Consumidor } \\
\text { Hombre urbano } \\
\text { Viajero/ocio } \\
\text { Entretenimiento } \\
\text { Amigo } \\
\text { Hombre consciente de su estilo/modelo } \\
\text { Otro }\end{array}$ \\
\hline & Cualidad o actitud & $\begin{array}{l}\text { Alegre/satisfecho } \\
\text { Triste/insatisfecho } \\
\text { Aventurero } \\
\text { Reservado } \\
\text { Racional } \\
\text { Imaginativo } \\
\text { Individualista } \\
\text { Sociable/cariñoso } \\
\text { Dependiente } \\
\text { Independiente } \\
\text { Seductor } \\
\text { Seriedad } \\
\text { Otro } \\
\text { Imposible determinar }\end{array}$ \\
\hline & $\begin{array}{c}\text { Espacio } \\
\text { predominante }\end{array}$ & $\begin{array}{l}\text { Interior } \\
\text { a) Hogar } \\
\text { b) Oficina } \\
\text { c) Plató/sesión fotográfica en estudio } \\
\text { d) Otros } \\
\text { Exterior } \\
\text { a) Rural, naturaleza } \\
\text { b) Urbano } \\
\text { c) Fantástico, onírico, imaginario } \\
\text { d) Descontextualizado } \\
\text { e) Tienda o gran superficie } \\
\text { f) Otro }\end{array}$ \\
\hline $\begin{array}{l}\text { Categorías } \\
\text { establecidas por } \\
\text { Erving Goffman }\end{array}$ & Compañía & $\begin{array}{l}\text { Solo } \\
\text { Con una o más mujeres } \\
\text { Con uno o más hombres } \\
\text { Con niños } \\
\text { Con otros hombres y mujeres } \\
\text { Otro }\end{array}$ \\
\hline
\end{tabular}




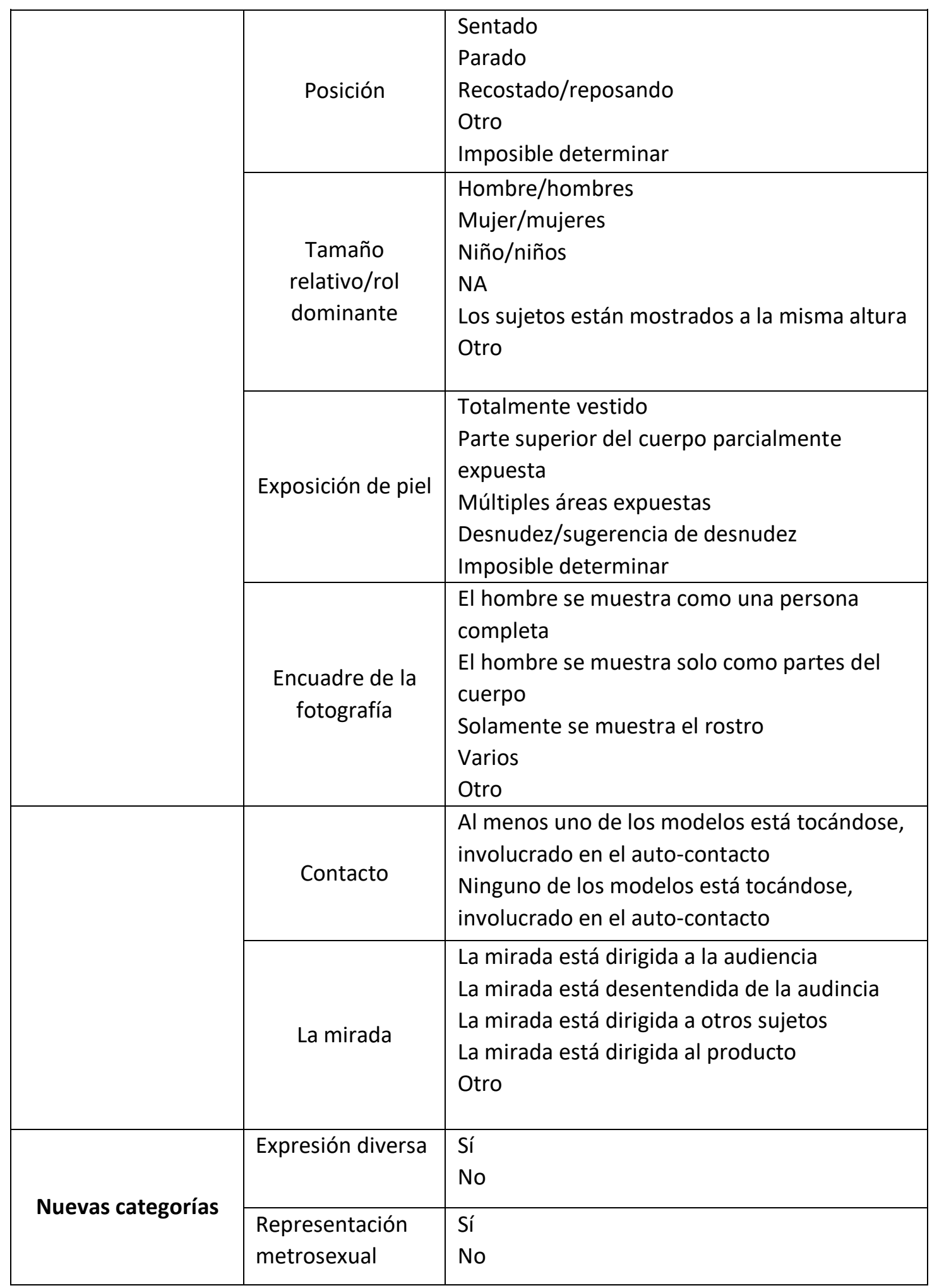

